\title{
Transformando lixo em arte: Um relato de experiência no ensino de Química
}

\author{
Transforming garbage into art: An experience report in Chemistry teaching \\ Transformar los resídos en arte: Un informe de experiencia en la enseñanza de la Química
}

Recebido: 01/06/2021 | Revisado: 13/06/2021 | Aceito: 18/06/2021 | Publicado: 02/07/2021

\author{
Yasmin Santos de Azevedo \\ ORCID: https://orcid.org/0000-0003-2034-4233 \\ Universidade do Estado do Pará, Brasil \\ E-mail: yasmin.azevedo@aluno.uepa.br \\ Clintia Cardoso Portilho \\ ORCID: https://orcid.org/0000-0001-9272-568X \\ Universidade do Estado do Pará, Brasil \\ E-mail:clintia.pontilho@aluno.uepa.br \\ Pablo Souza de Sá \\ ORCID: https://orcid.org/0000-0002-2766-796X \\ Universidade do Estado do Pará, Brasil \\ E-mail: pablo.sa@aluno.uepa.br \\ Nathália Barra Viana \\ ORCID: https://orcid.org/0000-0003-2299-4854 \\ Universidade do Estado do Pará, Brasil \\ E-mail: nathalia.viana@ aluno.uepa.br \\ Steven Souza Paes \\ ORCID: https://orcid.org/0000-0001-6135-8397 \\ Secretaria de Educação do Estado do Pará, Brasil \\ E-mail: steven.paes3574@escola.seduc.pa.gov.br \\ Manoel Leão Lopes Junior \\ ORCID: https://orcid.org/0000-0002-4675-6298 \\ Universidade do Estado do Pará, Brasil \\ E-mail: manoelleao@ufpa.br \\ Luely Oliveira da Silva \\ ORCID: https://orcid.org/0000-0002-5544-7438 \\ Universidade do Estado do Pará, Brasil \\ E-mail: luely.silva@uepa.br
}

\begin{abstract}
Resumo
Os resíduos sólidos constituem-se como um dos maiores poluidores do ambiente atualmente, acarretando sérios problemas ambientais, econômicos e sociais. Trabalhar essa problemática torna-se fundamental, sendo indispensável a mudança nas atitudes e mentalidade dos indivíduos. Nesse sentido, este trabalho visou construir e analisar ações pedagógicas a partir da problemática dos resíduos sólidos de uma praia, as quais foram articuladas com o ensino de Química. O estudo foi realizado com um grupo de 9 alunos do Curso Técnico em Meio Ambiente da região do Baixo Tocantins do estado do Pará. A metodologia baseou-se em uma abordagem qualitativa dentro da técnica de estudo de caso e análise de conteúdo. A pesquisa dividiu-se em 4 etapas: pesquisa bibliográfica em repositórios científicos; atividade de campo; elaboração, validação e aplicação de um questionário; por fim, a oficina temática "Transformando lixo em arte". Os resultados mostraram que a discussão de questões ambientais aliadas ao ensino de Química e a Arte propicia um ensino significativo, desenvolvendo o senso crítico e reflexivo sobre as situações problematizadas, contudo, ações como as propostas neste trabalho não devem ser vistas como respostas diretas para as questões ambientais ou dificuldades no processo de ensino-aprendizagem de Química.
\end{abstract}

Palavras-chave: Lixo; Arte; Ensino de química; Meio ambiente; Prática pedagógica.

\section{Abstract}

Solid waste is one of the biggest polluters of the environment in these days, causing serious environmental, economic and social problems. Working on this problem is necessary, and it is essential to change the attitudes and mentality of individuals. In this sense, this work aimed to build and analyze pedagogical actions based on the problem of solid waste in a beach, which were articulated with Chemistry Education. The study was carried out with a group of 9 students from the Technical Course on Environment in the region of Baixo Tocantins in the state of Pará. The methodology was based on a qualitative approach within the technique of case study and content analysis. The research was divided into 4 stages: bibliographic research in scientific repositories; field activity; elaboration, validation and application of a questionnaire; finally, the thematic workshop "Transforming garbage into art". The results showed that the discussion of environmental issues combined with the teaching of Chemistry and Art provides a meaningful teaching, developing a critical and reflective sense about problematized situations, however, actions 
such as those proposed in this work should not be seen as direct responses to environmental issues or difficulties in the teaching-learning process of Chemistry.

Keywords: Garbage; Chemistry education; Environment; Pedagogical practice.

\section{Resumen}

Los residuos sólidos son uno de los mayores contaminantes del medio ambiente en la actualidad, causando graves problemas ambientales, económicos y sociales. Trabajar este problema se vuelve fundamental, y es fundamental cambiar las actitudes y la mentalidad de los individuos. En este sentido, este trabajo tuvo como objetivo construir y analizar acciones pedagógicas basadas en la problemática de los residuos sólidos de la playa, las cuales se articularon con la enseñanza de la Química. El estudio se realizó con un grupo de 9 estudiantes del Curso Técnico de Medio Ambiente de la región del Baixo Tocantins en el estado de Pará, la metodología se basó en un enfoque cualitativo dentro de la técnica de estudio de caso y análisis de contenido. La investigación se dividió en 4 etapas: investigación bibliográfica en repositorios científicos; actividad de campo; elaboración, validación y aplicación de un cuestionario; finalmente, el taller temático "Transformando basura en arte". Los resultados mostraron que la discusión de temas ambientales combinada con la enseñanza de la Química y el Arte brinda una enseñanza significativa, desarrollando un sentido crítico y reflexivo sobre situaciones problematizadas, sin embargo, acciones como las propuestas en este trabajo no deben ser vistas como respuestas directas a las cuestiones, problemas ambientales o dificultades en el proceso de enseñanza-aprendizaje de la Química.

Palabras clave: Basura; Arte; Enseñanza de la química; Medio ambiente; Práctica pedagógica.

\section{Introdução}

O lixo é um dos grandes problemas do século e constitui uma preocupação ambiental mundial. O crescimento desordenado das cidades tem grande relação com o acúmulo do lixo, que promove a destruição ambiental e põe em risco a qualidade de vida. Diariamente são produzidas toneladas de lixo, cujos destino correto e reaproveitamento tornam-se uma grande preocupação. Nesse sentido, o cenário dos problemas ambientais requer estudos relacionados a questões do lixo, buscando desenvolvimento de tecnologias e estratégias em prol do ambiente, buscando esclarecer questionamentos e entender as relações homem natureza de forma integral (Rabelo, et al., 2020).

Portanto, a educação ambiental assume um papel fundamental e transformadora nas questões do desenvolvimento sustentável e socioambientais. É importante considerar que a educação ambiental atravessa vários campos do conhecimento, sendo vista como um processo permanente de aprendizagem. No contexto escolar, campo das discussões deste artigo, apontase para propostas pedagógicas centradas na conscientização, desenvolvimento de competências e habilidades dos educandos (Reigota, 1998).

Diante desse cenário, nota-se a relevância de se trabalhar a educação ambiental no âmbito escolar desde as séries iniciais, como propõem a Base Nacional Comum Curricular (BNCC) e os Parâmetros Curriculares Nacionais (PCN), com o intuito de provocar no sujeito uma reflexão e mudança de postura diante do meio ambiente. Tal abordagem deve ser feita de forma transversal e interdisciplinar, contribuindo para o fortalecimento do processo de conscientização a respeito da necessidade de preservação.

Estabelecer uma boa relação homem-natureza é primordial para a transformação socioambiental de um lugar. Lugar este não somente no sentido geográfico de localização, mas enquanto espaço da convivência dos indivíduos, como ambiente que provoca a presença, emoção e sensibilização, onde a aplicação de ações pedagógicas para a educação ambiental aliadas à arte poderá alcançar o sentido além do racional da aprendizagem, mas também da sensibilidade. Diante disto, os objetos artísticos podem ampliar os canais de comunicação do ser para a emoção, intuição e associações (Coli, 1995).

O local da pesquisa situa-se às margens de um igarapé localizado na praia da Aldeia, no município de Cametá-PA, sendo muito conhecido e frequentado por banhistas e turistas, onde a coleta dos resíduos é inexistente. São inúmeros os impactos causados pelo lixo persistente nos ambientes costeiros e marinhos, sendo os principais: riscos para a saúde; toxicidade ecológica e química; aprisionamento de animais e perigos de ingestão; entre outros (Gregory, 1999). 
As escolas geralmente abordam a educação ambiental de forma minimalista e relacionam, em geral, com desperdício de recursos naturais e de cuidados com a natureza, contudo, sabe-se que esta é muito mais extensa e necessita ser ampliada e aprofundada no âmbito escolar. Em relação ao ensino de Química, muitos pesquisadores afirmam que se deve adotar uma nova abordagem, seguido de um trabalho que associe o conhecimento químico de maneira problematizada à realidade social em que o aluno se insere (Arrigo, Alexandre, \& Assai, 2018).

Trabalhar a educação ambiental através da disciplina de Química relacionando com a arte pode consistir uma excelente estratégia de ensino, tendo apoio nos PCNs e na BNCC (Base Nacional Comum Curricular), que recomendam o uso de temas transversais e a organização interdisciplinar do currículo. A arte pode compor uma abordagem mais humanística e integrada para a aula de Química, contribuindo para alcançar a construção do conhecimento (Gatti, Carvalho, \& Afonso, 2018).

A formação de uma conscientização socioambiental abrange tanto a mudança ética do comportamento humano, como a relação do indivíduo com os conteúdos curriculares. Entretanto, no contexto escolar, percebe-se que a realidade da educação ambiental ainda se distancia do processo de escolarização do aluno, tornando-se necessárias práticas pedagógicas sobre o meio ambiente aliadas ao ensino de Química, relacionando ciência, tecnologia e sociedade.

Tem-se comumente exemplos de práticas pedagógicas sobre o meio ambiente nas abordagens relacionadas ao reaproveitamento do lixo, conforme Silva, Fernandes e Campos (2014), que salientam que a abordagem desse tema em sala de aula representa um aspecto importante para a formação dos alunos, no sentido de desenvolver conhecimentos relativos a essa problemática e, ao mesmo tempo, sensibilizá-los sobre as diversas questões associadas ao lixo, podendo assim denotar o compromisso social da ciência (Cachapuz, Carvalho, \& Gil-Pérez; 2012).

Refletindo acerca do contexto do ensino de Química, Andrade, Barros e Vasconcelos (2016) consideram que dar ênfase ao ambiente facilita a compreensão do conhecimento químico na sociedade, pois a temática socioambiental poderá ser um instrumento didático na escola para contextualização do conhecimento, discutindo a importância de alguns conceitos no dia a dia, mantendo a conexão da Química com a realidade. Desse modo, o ensino de Química contextualizado com temas socioambientais possibilita a relação do conhecimento científico e o mundo real, evidenciado pela necessidade de uma alfabetização sociocientífica sobre temas que relacionam a ciência, tecnologia, sociedade (CTS) e sustentabilidade.

Neste sentido, na perspectiva sócio-histórica de Vygotsky entende-se que para o desenvolvimento cognitivo do ser humano tem-se como referência o contexto social e cultural no qual ele ocorre, onde as habilidades cognitivas se desenvolvem por meio das interações do meio social, do contrário inviabilizaria o entendimento de uma ideia na totalidade (Moreira, 2011).

Ainda na perspectiva do ensino de Química, as investigações dedicadas em compreender e propor estratégias que minimizem as adversidades, comumente encontradas no ensino desta ciência, relatam o uso da arte como estratégia educativa. Como relatado por Halpine (2004), a Universidade da Califórnia nos Estados Unidos buscou solucionar a problemática da falta de profissionais nas áreas de Ciência e Tecnologia no estado americano, com isso foi criado um programa intitulado "STart Ensinando ciências através da arte", este projeto foi incorporado ao currículo educacional do Estado e, ao longo da sua aplicação, foi possível constatar um maior interesse e participação dos alunos nas aulas de ciências quando se utilizava formas artísticas de Química, Física e Biologia.

Nesse sentido, este trabalho busca construir e analisar ações pedagógicas a partir da problemática dos resíduos sólidos na praia, as quais foram articuladas com o ensino de Química, com o intuito de identificar as implicações que a temática permite relacionar ciência, tecnologia e sociedade, a contextualização do ensino de Química, a Educação Ambiental e Arte na Química, bem como, contribuir para uma ação consciente e responsável frente aos resíduos sólidos. 


\section{Metodologia}

A pesquisa foi realizada com um grupo de 9 alunos de uma turma de um Curso Técnico em Meio Ambiente da região do Baixo Tocantins no estado do Pará, com uma metodologia baseada em uma abordagem qualitativa dentro da técnica de estudo de caso (Portinari, 2011) E Os Dados Foram Coletados Por Meio De Pesquisa Bibliográfica (Lüdke, \& André, 1986), Observação Não Participante (Cervo, Bervian, \& Silva, 2007) e questionário validado por opinião de especialistas (Supo, 2012), sendo estes professores do Curso de Graduação em Ciências Naturais da Universidade Estadual do Pará.

Os procedimentos da pesquisa podem ser divididos em quatro etapas (Quadro 1), iniciando a Etapa 1 pela pesquisa bibliográfica em repositórios científicos sobre abordagens do ensino de Química a partir de uma perspectiva ambiental. A Etapa 2 se consistiu na realização de uma atividade de campo com os participantes da pesquisa, realizada em uma área determinada da praia do município, localizada às margens de um igarapé. Em seguida, a Etapa 3 teve a elaboração, validação e aplicação de um questionário aos estudantes. Por fim, a Etapa 4 ocorreu a partir da realização de uma oficina temática "Transformando Lixo em Arte".

Quadro 1. Caracterização das etapas da pesquisa.

\begin{tabular}{|l|l|}
\hline \multicolumn{1}{|c|}{ Etapa } & \multicolumn{1}{c|}{ Finalidade } \\
\hline 1. Pesquisa bibliográfica & $\begin{array}{l}\text { Coletar dados que permitem conhecer e consolidar as categorias estruturais da } \\
\text { educação. }\end{array}$ \\
\hline 2. Atividade de campo & $\begin{array}{l}\text { Conhecer e vivenciar a realidade do ambiente natural (praia) modificada pelo } \\
\text { homem. }\end{array}$ \\
\hline 3. Aplicação dos questionários & Identificaras concepções dos estudantes e implicações da vivência realizada. \\
\hline 4. Oficina temática & Lançar uma ação pedagógica com potencial articulação ao ensino de Química. \\
\hline
\end{tabular}

Fonte: Autores.

A coleta de dados ocorreu de duas maneiras: a primeira por meio da observação não participante durante a atividade de campo (Etapa 2). Neste momento, após a ambientação dos estudantes na praia, foi realizado um bate-papo com eles por meio de uma roda de conversa (Campos, 2006), em seguida ocorreu a retirada de resíduos do local com auxílio de luvas e baldes, posteriormente, foi feita a separação de materiais como garrafas de vidro, pets, plásticos e outros materiais que poderiam ser reutilizados na Etapa 3. E ainda, com a observação não participante, ocorreu a realização da oficina, em que os alunos foram convidados a reaproveitar os resíduos coletados e transformá-los em objetos artísticos e decorativos conforme a criatividade de cada participante.

A segunda maneira refere-se à montagem de categorias estruturais da informação (Oliveira, 2016), coletada na pesquisa bibliográfica e na aplicação dos questionários, sendo estas categorias: Tema sócio-científico para o ensino de Química (CTSA); A contextualização do ensino (a química do lixo); A Arte e a Química; Projetos de educação ambiental (motivador para o ensino de Química). Para examinar os relatos apresentados no questionário, foi feita uma aproximação da técnica de análise de conteúdo de Bardin (2008) com as categorias estruturais, pois é um método empírico que auxilia na interpretação da "fala" e no que se pretende como objetivo.

\section{Resultados e Discussão}

Em uma pré-análise, selecionou-se na pesquisa bibliográfica os documentos oficiais da Educação no Brasil, como a BNCC e os PCNs, bem como alguns pesquisadores dedicados ao ensino de Química: Chassot (2008); Schwartz (2006); Mahaffy at. al. (2019). Essas escolhas foram baseadas na representatividade, homogeneidade e pertinência, deixando-se invadir 
pelas impressões e orientações na pré-análise, realizou-se uma leitura flutuante das respostas dos questionários aplicados aos estudantes, que deu origem à nuvem de palavras (Figura1), definindo-se assim o corpus da pesquisa.

Seguindo o desenvolvimento da análise de conteúdo, iniciou-se a exploração do material dedicado em identificar "unidades de registro e de contexto" (Bardin, 2008), em que se verificou a presença/frequência de termos com valor semântico inter-relacionado, visando à categorização estrutural no que diz respeito à associação do lixo com a arte, e o fazer pedagógico da escola associado às práticas de conservação ambiental em um contexto de múltiplas abordagens para a realização de um ensino de Química significativo.

Figura 1. Nuvem de palavras mais frequentes nas respostas dos alunos

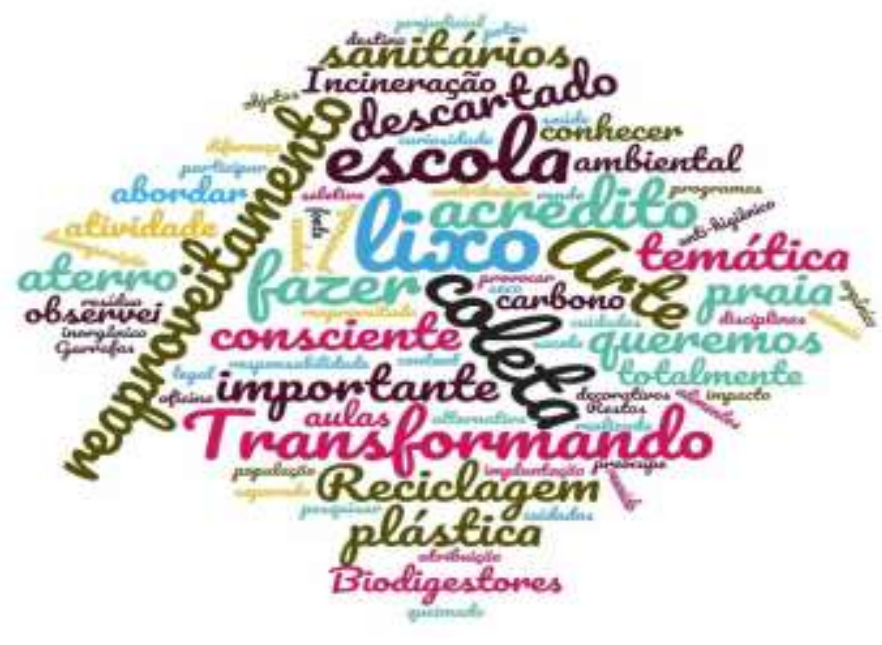

Fonte: Autores.

Quanto ao tratamento dos resultados, a inferência e a interpretação foram suportes para a categorização interpelada neste trabalho, considerando critérios de qualidade nesta escolha. Logo, cada categoria funcionou como uma dimensão de análise (homogeneidade), estando adaptada ao material de análise e ao quadro teórico definido (pertinência), sendo elas: CTSA, contextualização, abordagens temáticas e projetos de educação ambiental.

Sendo assim, o levantamento bibliográfico realizado na Etapa 1 possibilitou a construção de um infográfico (Figura 2), que apresenta uma visão geral das abordagens da Educação em Química na perspectiva ambiental, sendo a sistematização das categorias estruturais das informações construída a partir deste levantamento bibliográfico, de acordo com a proposta pedagógica apresentada neste trabalho, que buscou assumir uma posição epistemológica do compromisso social da ciência, reconhecendo-a como integrante da cultura, buscando o desenvolvimento de atividades científicas, com a necessária compreensão, e não como produto final da informação (Cachapuz, Carvalho, \& Gil-Pérez; 2012). 
Figura 2. Infográfico das informações estruturais da pesquisa.

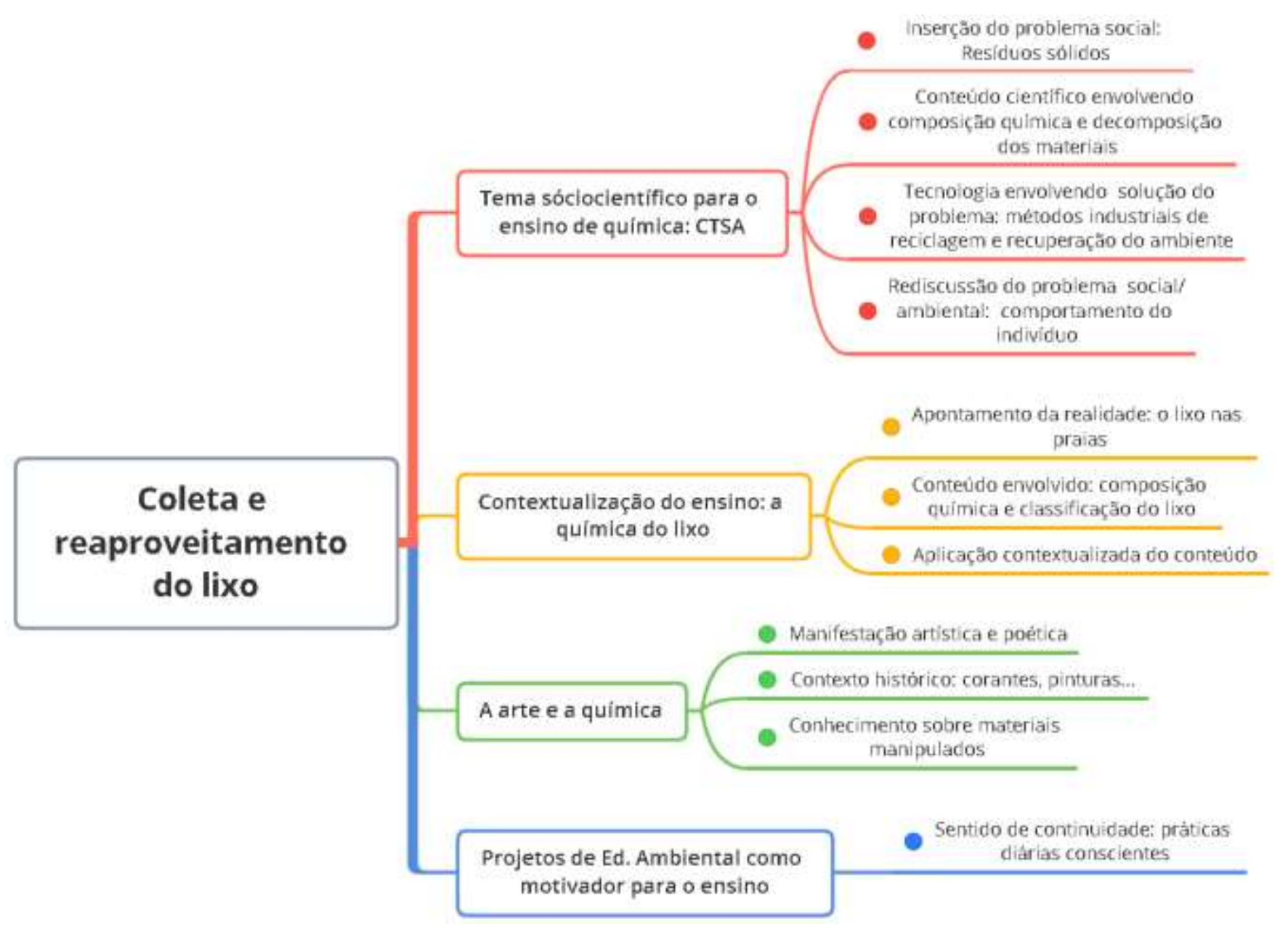

Fonte: Autores.

Com base nos dados, estabeleceu-se categorias na análise de cada resposta/dado, visando sempre aos objetivos da investigação, o qual se apresenta na análise de descrição desses dados.

As primeiras questões do questionário aplicado levam os participantes a realizar uma descrição sobre as observações feitas na área de estudo. Como ponto inicial, os estudantes relataram a presença de um grande volume de resíduos sólidos dispersos no local, destacando objetos como: garrafas pet, vidros, bitucas de cigarro e sacos plásticos, além de perceber a falta de lixeiras e coleta regular de lixo, desmatamento, falta de saneamento básico ou tratamento de água, assim como a presença de animais como cães, pássaros e cobras, ressaltando a reciclagem e reaproveitamento como a melhor opção de destino do lixo e a incineração como a pior forma de destino.

A partir dessas observações, tem-se a focalização em um problema que envolve questões ambientais, bem como sociais, em que o estudante tende a realizar uma compreensão pessoal do ambiente, chegando a uma concepção de desequilíbrio ambiental, sendo este aspecto motivador para promover o interesse dos educandos acerca da compreensão da natureza, convidando-os a busca de alternativas de aplicação da ciência e tecnologia dentro da visão do bem-estar social e ambiental, sendo estes pressupostos para um ensino na perspectiva Ciência Tecnologia e Sociedade (CTS) (Santos, \& Schnetzler, 2010) .

Todos os estudantes revelaram a percepção crítica dos efeitos até mesmo irreversíveis dos resíduos presentes no ambiente natural (praia) para o solo e para a água. Auler e Bazzo (2001) relatam que um dos objetivos do movimento CTS é 
promover o interesse dos educandos em relacionar ciência com aplicações tecnológicas e os fenômenos da vida cotidiana. Sabe-se que a degradação ambiental representa uma ameaça à saúde pública (Marques, 2011), tão logo uma questão ambiental pode ser introduzida no contexto escolar, abrindo espaço para discussões do efeito da tecnologia e da ciência na sociedade, no sentido de buscar o desenvolvimento de teorias científicas e tecnologias que possam influenciar a maneira como as pessoas pensam sobre si próprias, sobre os problemas, questões ambientais e soluções (Santos, \& Mortimer, 2000).

Santos e Mortimer (2000) consideram que a reorganização crítica e reflexiva dos conteúdos diminui a distância entre a Educação Básica e a Superior, bem como envolve o estudante com a sua realidade socioambiental. Assim, essa abordagem busca propiciar o maior acréscimo de consciência a respeito dessas interações, quebrando o papel neutro da ciência e desenvolvendo a habilidade crítica do indivíduo frente a problemas de seu contexto atual. Isso pode ser observado nas respostas de 7 alunos participantes (Gráfico 1), que vislumbram que o lixo, com os devidos cuidados, tem potencial em ser uma fonte de renda para população, evidenciando assim a visão crítica do indivíduo diante do contexto do problema ambiental e consequente influência em questões sociais.

Nesse sentido, a Educação em Química na abordagem do CTS pode ser estimulada por meio de atividades de campo que envolvam a observação do meio ambiente pela inserção de uma situação problema - aqui foram os resíduos sólidos. Após este ponto de partida, é possível desenvolver a discussão do conteúdo científico, sendo a composição química dos materiais identificada pelos alunos, bem como, o tempo de decomposição desses materiais.

Logo, é viável introduzir uma abordagem tecnológica para resolver o problema observado, que pode ser através de métodos industriais de reciclagem e recuperação ambiental. Assim, para o cenário pedagógico então criado, existe a possibilidade de uma rediscussão do problema socioambiental no que se refere ao comportamento do indivíduo, pois, quando o aluno conhece seu mundo e sua própria realidade, ele é capaz de realizar ações para transformar o mundo em torno dele (Silva, \& Araújo, 2014).

Gráfico 1. Respostas da pergunta: "Você acredita que o lixo pode se tornar uma fonte de renda para a população?".

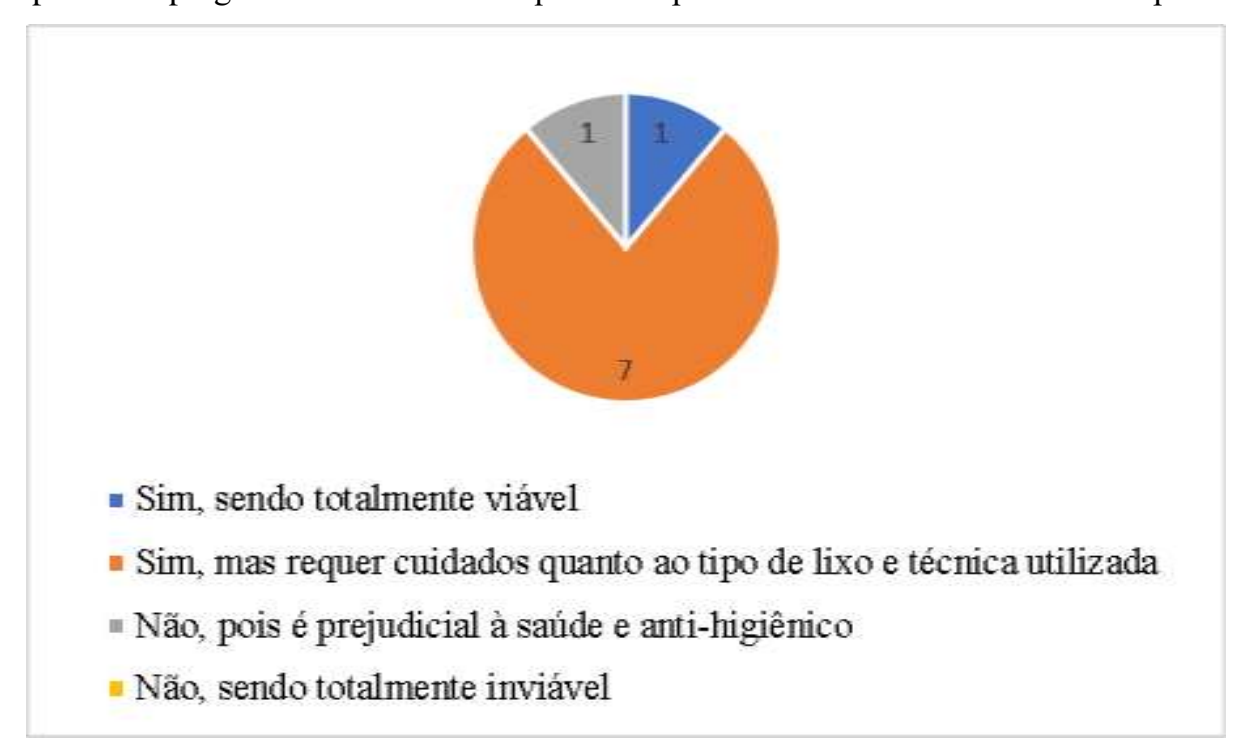

Fonte: Autores.

Ainda na coleta de dados desta pesquisa, os alunos relataram as práticas comuns do seu dia a dia a respeito da gestão do lixo (Tabela 1), sendo esta uma oportunidade de o educador conhecer a realidade do educando, bem como o nível de informações adquiridas, o que possibilita a prática de um ensino de química contextualizado, considerando que na 
contextualização deve haver a vinculação do conteúdo trabalhado na sala de aula e o contexto social que o aluno está inserido (Santos, \& Mortimer, 2010).

Tabela 1. Informações referente às respostas dos alunos.

\begin{tabular}{|l|l|l|}
\hline \multicolumn{2}{|c|}{ Questionamento } & \multicolumn{2}{c|}{ Respostas Obtidas } \\
\hline $\begin{array}{l}\text { Como o lixo é descartado na sua } \\
\text { casa? }\end{array}$ & $\begin{array}{l}\text { 8 alunos colocam seu lixo em sacolas plásticas e } \\
\text { descarta em pontos de coleta }\end{array}$ & $\begin{array}{l}\text { 1 aluno separa o lixo e descarta em pontos } \\
\text { de coletas }\end{array}$ \\
\hline $\begin{array}{l}\text { Você sabe a diferença entre lixo } \\
\text { orgânico e o inorgânico? }\end{array}$ & $\begin{array}{l}7 \text { alunos sabem a diferença entre lixo orgânico e } \\
\text { inorgânico }\end{array}$ & $\begin{array}{l}2 \text { alunos têm dúvidas quanto à diferença na } \\
\text { classificação do lixo }\end{array}$ \\
\hline
\end{tabular}

Fonte: Autores.

Seguindo com as reflexões e abordagens da contextualização do ensino, 8 entrevistados disseram que se sentem curiosos sobre o tempo de decomposição dos resíduos sólidos, informando sobre o tempo médio que acreditavam que o material tinha até sofrer decomposição. O despertar para a conscientização em relação ao meio ambiente é uma necessidade, podendo ser alcançada a partir dos desafios colocados pela sociedade (Loureiro et al., 2009), em que o educador com abordagens históricas e socioculturais poderá levar a sala de aula as considerações dos estudantes sobre a implantação da coleta seletiva (todos destacaram a importância da coleta seletiva), programas de reciclagem e o aterro sanitário (Quadro 2), destacando aspectos acerca da importância da coleta seletiva, as questões de saúde pública e a questão social.

Quadro 2. Transcrição de algumas respostas dos estudantes.

Você considera importante a implantação da coleta seletiva, programas de reciclagem e o aterro sanitário? Por quê??

“[...] a implementação de aterros sanitários, juntamente com a coleta seletiva, iria solucionar parte dos problemas que as cidades enfrentam com os resíduos”.

“o aterro é importante quanto para saúde e para conversação do meio ambiente”.

"não só para ajudar o meio ambiente, mas ajudaria as pessoas que fossem trabalhar no ramo"; "vai beneficiar tanto o meio ambientes quanto a população q moram próximos".

Fonte: Autores.

Com o intuito de investigar a compreensão dos alunos sobre a relação lixo e arte e como esses itens podem ter uma importante função social, levantou-se alguns questionamentos, em que todos os discentes afirmaram que existe essa conexão, dá-se ênfase ao fato de que a percepção crítica dos alunos foi além do esperado, quando eles citaram benefícios em relação a aspectos econômicos que o lixo pode atribuir para a sociedade, pois materiais que serão descartados no meio ambiente podem transformar-se em objetos de "luxo" (Scamati, \& Lima, 2017), passíveis de se constituir em geração de renda para famílias em situação de vulnerabilidade social e econômica, colaborando para a diminuição do descarte de resíduos considerados inservíveis para o uso humano.

Nesse sentido, é possível constatar que através da arte o homem interpreta sua própria natureza, construindo formas ao mesmo tempo em que se descobre, inventa, figura e conhece (Buoro, 2001). A arte é uma estratégia de desenvolvimento que mobiliza experiências, percepções e reflexões significativas acerca dos processos educacionais e socioambientais (Silva, \& Batista). 
Refletindo sobre os processos criativos, Ostrower (1977, p.1 87) explicou que estes não se limitam somente ao campo das Artes, estando presente nas mais diversas áreas do conhecimento humano. Na perspectiva deste trabalho, Barros e Layoun (2018) discutem a educação ambiental com foco na reutilização e redução dos resíduos numa abordagem artística, onde o lixo e a sucata entram como material de pesquisa, de colagem e de construção, dando origem a objetos que favorecem a discussão e sensibilização dos problemas que envolvem a relação homem/natureza.

Em referência ao âmbito escolar, a maior parte dos alunos demonstrou reconhecer a importância da instituição em abordar a temática, de forma que para eles, a escola é fundamental para a aquisição de uma consciência ambiental, afirmações estas apresentadas no Gráfico 2. Considera-se então que a incorporação da educação ambiental pode atingir os demais segmentos da sociedade, cuja inserção da dimensão ambiental proporciona a realização de um trabalho contínuo e permanente, e as transformações alcançadas transpõem os muros da escola (Silva, 1995).

Gráfico 2. Respostas da pergunta “na sua opinião as escolas deveriam abordar o tema lixo?”.

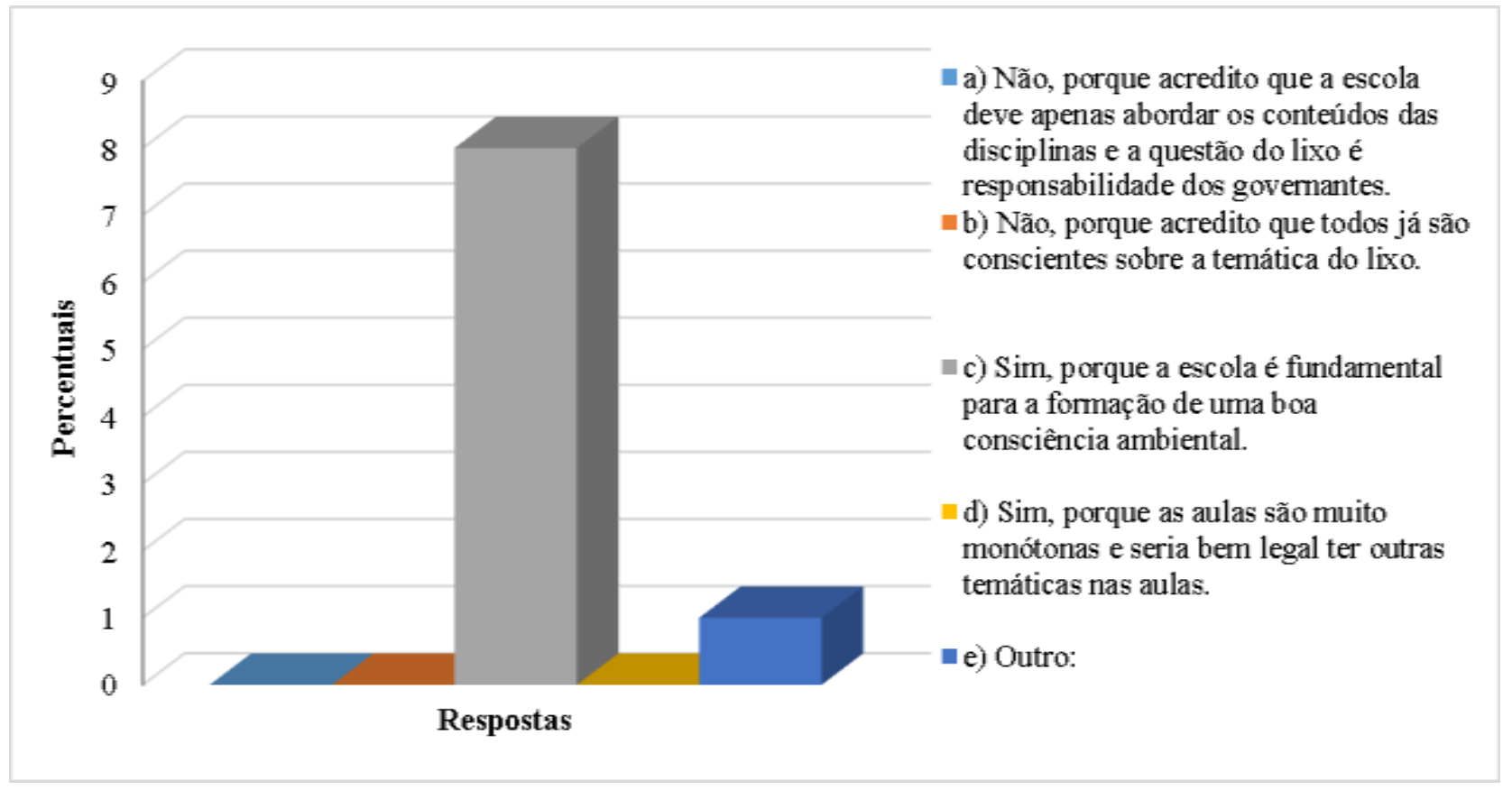

Fonte: Autores.

Buscando a inserção dos alunos como participantes ativos na construção do conhecimento, solicitou que eles sugerissem novas formas de destino para o lixo, por meio de perguntas relacionadas à criatividade artística, sendo possível constatar que uma parte considerável dos alunos (7) não conseguiu sugerir uma nova atribuição para o lixo, no entanto, a maioria dos investigados apontou ideias satisfatórias, sobre atividades artísticas que deveriam ser realizadas pelas escola, como as observadas no Quadro 3: 
Quadro 3. Transcrição de algumas respostas dos estudantes.

\begin{tabular}{|l|}
\hline Você tem alguma sugestão de atividade artística que possa ser realizada na escola para reaproveitamento do lixo? \\
\hline $\begin{array}{l}\text { "Poderiam ensinar as crianças q nem tudo é lixo, e levar um exemplo de coisas que foram reaproveitadas para q elas } \\
\text { possam ver o quão grande é a importância do reaproveitamento do lixo }\end{array}$ \\
\hline $\begin{array}{l}\text { "O saco plástico é algo que vem sendo muito descartado, então seria uma boa ideia trabalhar o reaproveitamento dele na } \\
\text { criação de objetos" }\end{array}$ \\
\hline "Uma exposição de trabalhos feitos com o lixo reciclado" \\
\hline
\end{tabular}

Fonte: Autores.

Com isso é possível apontar que o estudante "cresce formando-se como protagonista na transformação por busca de soluções para os problemas ambientais torna-se elemento ativo no processo participativo e solidário da educação ambiental" (Siqueira, \& Arrial, 2018).

$\mathrm{Na}$ última etapa da pesquisa (Etapa 4), realizou-se a reutilização dos resíduos coletados na etapa anterior, por meio de uma oficina temática "Transformando Lixo em Arte". Provocando a criatividade dos alunos, iniciou-se a confecção de novos objetos, que depois com outras utilidades e aparências deixaram de ser categorizados como lixo, expostos na Figura 3. Dessa maneira, a reutilização também está ao alcance de todos, na função original ou com um pouco de criatividade, podemos é possível inventar/criar muitas coisas (Scanavaca Junior, 2012).

Figura 3. Oficina com a reutilização dos materiais coletados.

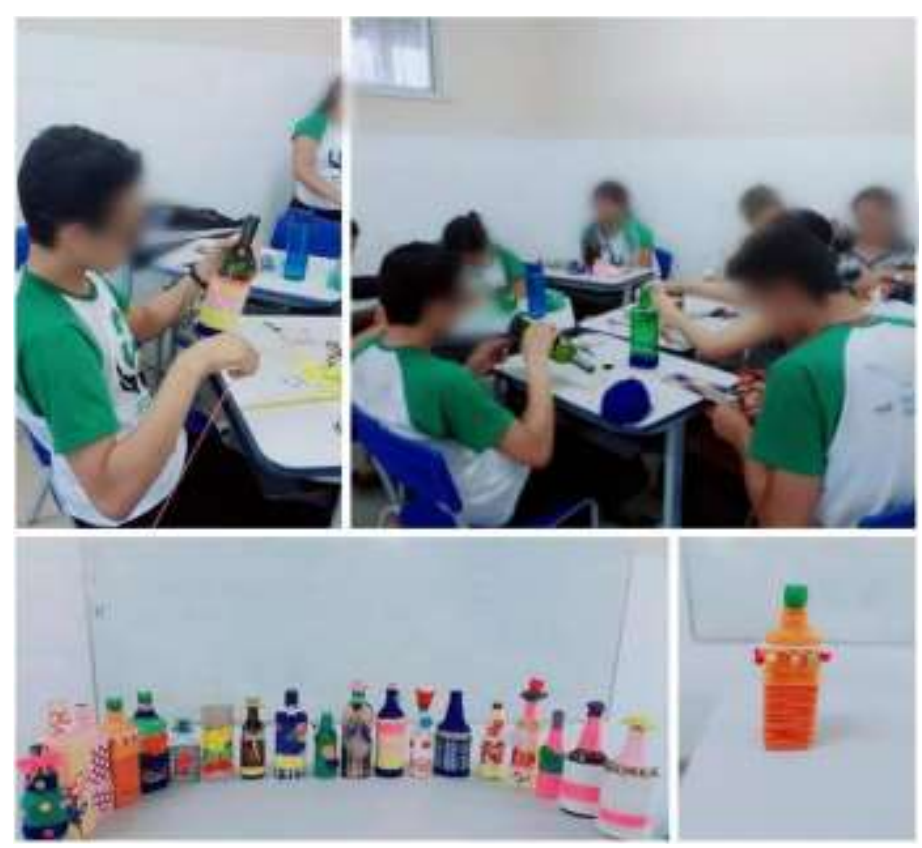

Fonte: Autores.

Aliadas dessa prática artística, as ações pedagógicas voltadas para o desenvolvimento integral do aluno são indispensáveis. Por meio das observações não participativas na oficina, percebe-se o atrelamento das questões ambientais como suporte para o ensino de Química, que propiciou aos estudantes uma compreensão científica e crítica sobre a 
problemática social do lixo. Com as ações desenvolvidas, mostra-se ser possível ensinar conceitos químicos de modo contextualizado sobre essa temática, provendo conhecimentos pertinentes sobre o assunto (Santos et al., 2011).

Em concordância com a atividade realizada, foram marcantes as falas de alguns alunos diante das novas abordagens CTSA, como: "agora vou aproveitar tudo em casa"; "minha casa vai ter uma nova decoração"; "não achava que demorava tanto tempo para decompor", "nem passava pela minha cabeça que ia ficar tão lindo"; "uma ótima alternativa para diminuir a poluição da praia". Sendo assim, por meio dessa atividade, efetivou-se uma pequena ação de incentivo à conscientização ambiental, contextualizada ao ensino de Química, que proporcionou consequências boas ao meio ambiente e possibilitou um ensino-aprendizagem de Química mais significativo.

Ao ressignificar situações ou ações por meio de práticas pedagógicas que potencializam a dialogicidade para o ensino de ciências, envolve-se o aluno no processo de aprendizagem construtivista, bem chamado por Vygotsky como recontrutivismo, pois o indivíduo primeiro internaliza, depois reconstrói internamente na sua estrutura cognitiva por meio da interação com o contexto sócio-históricocultural (Moreira, 2001).

Desta forma, deseja-se que temáticas ambientais possam fazer parte da rotina escolar como possibilidades para o ensino de Química, contribuindo de forma significativa com as propostas curriculares para a educação básica.

\section{Conclusão}

A arte e o lixo se relacionam quando seus significados são definidos em uma perspectiva para o incentivo à consciência ambiental, em que atividades didáticas pautadas na problematização do lixo possibilitam o desenvolvimento de um ensino de Química contextualizado, significativo, estabelecendo relações dos conteúdos com ocorrências no meio ambiente. O enfoque científico e tecnológico do ensino de Química calcado em questões ambientais é uma premissa para a abordagem CTSA, que pode balizar projetos pedagógicos de educação ambiental nas instituições da Educação Básica.

Este trabalhou desenvolveu e aplicou uma proposta pedagógica que reconhece o compromisso social da ciência, bem como, a necessidade de explorar abordagens transformadoras e reflexivas para o ensino de química por meio do CTSA, da contextualização, da educação ambiental e da arte. Assim, os resultados desta pesquisa revelam que ações como a oficina realizada "Transformando Lixo em Arte" propiciam uma maior participação dos alunos, facilitam o desenvolvimento do pensamento complexo relacionado à Química de forma reflexiva e crítica, e ainda abordam situações problemáticas que incentivam a participação dos alunos na busca por melhorias/soluções.

Os autores deste trabalho concordam que atividades, como as oficinas que se restringem ao desenvolvimento de alguns dias, não devem ser concebidas como soluções práticas e imediatas para questões que envolvem problemas ambientais, nem para as dificuldades no processo de ensino-aprendizagem de Química. Defende-se, pois, o sentido de continuidade, que implica em resultados significativos e impactantes para todos os autores educacionais (professores e alunos). Essa premissa é apoiada levando-se em consideração as reflexões dos estudantes participantes da pesquisa, que revelam a concordância que escola, alunos, professores e meio ambiente são fundamentais para a transformação do indivíduo, desde que estejam relacionados a integrar conhecimentos, aptidões, valores e consequentemente ações conscientes.

\section{Referências}

Andrade, L.G.; Barros, J. K. C., \&Vasconcelos, E. R. (2016). Questões socioambientais e ensino da Química: perspectivas e demandas no contexto do ENEQ 2010-2012. Revista Brasileira de Educação Ambiental (RevBEA), 11(1), 85-96.

Arrigo, V., Alexandre, M. C. L., \& Assai, N. D. S. (2018). O Ensino de Química e a Educação Ambiental: uma proposta para trabalhar conteúdos de pilhas e baterias. Experiências em ensino de Química, 13 (5).

Auler, D., \& Bazzo, W. A. (2001). Reflexões para a implementação do movimento CTS no contexto educacional brasileiro. Ciência \& Educação, 7(1), 1-13. 
Bardin, L. (2008). Análise de Conteúdo. Edições 70.

Barros, A.G., \& Layoun, B.R.(2018). Arte regional de Mato Grosso do Sul: a Educação Ambiental e as aulas de arte. Revista Brasileira de Educação Ambiental (RevBEA), 13 (3), 26-41.

Brasil. (1997). Parâmetros curriculares nacionais: Introdução. MEC/SE.

Brasil. (2017). Base Nacional Comum Curricular. MEC/SE.

Buoro, A. B. (2001). O olhar em construção: uma experiência de ensino e aprendizagem da arte na escola. Cortez.

Cachapuz, A., Carvalho, A. M. P. \& Gil-Pérez, D. (2012). O ensino de ciências como compromisso científico e social:caminhos que percorremos. São Paulo: Cortez.

Campos, G. W. S.(2006). Efeito Paidéia e o campo da saúde: reflexões sobre a relação entre o sujeito e o mundo da vida. Trabalho, Educação e Saúde, 4 (1), 19-31.

Cervo, A. L., Bervian, P. A., \& Silva, R. (2007). Metodologia científica. Pearson Prentice Hall.

Chassot, A. (2008). Fazendo Educação em Ciências em um curso de Pedagogia com inclusão de Saberes Populares no currículo. Química Nova na Escola, 27.

Coli, J. (1995). O que é arte. Editora Brasiliense.

Gatti, I. M. C., Carvalho, F. O., \& Afonso, A. F. (2018). Química e arte contemporânea: uma abordagem interdisciplinar do tema lixo eletrônico. Revista Debates em Ensino de Química, 4 (2), 95-117.

Gregory, M. R.(1999). Plastics and South Pacific Islandshores: environmentalimplications. Ocean \& Coastal Management, 42 (6-7), 603-615.

Halpine, S. M.(2004). Introducing molecular visualization to primary schools in California: The STArt! teaching science through art program. Journal of Chemical Education, 81(10), 1431.

Loureiro, C. F. B.et al. (2009). Repensar a educação ambiental: um olhar crítico. Cortez.

Lüdke, M., \& André, M. E.D.A(1986). Pesquisa em educação: abordagens qualitativas. EPU.

Mahaffy, P. G. et al. (2019). Systems thinking. for education about the molecular basis of sustainability. Nature Sustainability, 2 (5), $362-370$.

Marques, R.F.P.V.(2011). Impactos Ambientais da Disposição de Resíduos Sólidos Urbanos no Solo e na Água Superficial em Três Municípios em Minas Gerais. Dissertação de Mestrado, em Recursos Hídricos em Sistemas Agrícolas, Universidade Federal de Lavras, Minas Gerais, Brasil.

Moreira, M. A. (2011). Teorias da aprendizagem. (2a ed.), EPU.

Oliveira, M. M. (2016). Como fazer pesquisa qualitativa. Vozes.

Ostrower, F. (1977). Criatividade e processos criativos. Vozes.

Portinari, J.C.(2011). Mais do que um documento testemunhal - Cândido Portinari: "Trabalho de amor e técnica". In Linhares, C. (Org.) Portinari e a cultura brasileira: um convite à educação a contrapelo. Eduff. .

Reigota, M. (1998). Desafios à educação ambiental escolar. In Jacobi, P. et al. (Orgs.). Educação, meio ambiente e cidadania: reflexões e experiências (pp. 4350). São Paulo: SMA.

Rabelo, J. P. M. (2020). Reflexões sobre a importância dos trabalhos de campo para os estudos em Ciências Ambientais. Research, Society and Development, $9(9), 1-15$.

Santos, P. T. A. et al. (2011). Lixo e Reciclagem como tema motivador no Ensino de Química. Eclética Química, 36 (1), 78-92.

Santos, W. L. P., \& Mortimer, E. F.(2000). Uma análise de pressupostos teóricos da abordagem C-T-S (Ciência - Tecnologia - Sociedade) no contexto da educação brasileira. Ensaio Pesquisa em Educação em Ciências, 2(2), 110-132.

Santos, W. L. P., \& Schnetzler, R. P. (2010). Educação em Química: Compromisso com a Cidadania. Ijuí: Unijuí.

Scamati, R. L. B., \& Lima, L. D. S. C.(2017). Luxo do lixo: a arte scrapbooking como ferramenta de Educação Ambiental. Revista Brasileira de Educação Ambiental, 12(2), 34-55.

Scanavaca Junior, L. (2012). O lixo e a necessidade de reduzir, reutilizar, reciclar e repensar, Boletim Paulista de Geografia, 73.

Schwartz, A. T. (2006). Educação química contextualizada: A experiência americana. Int. J. Sci. Educ., 28 (9), $977-998$.

Silva, M. M. P.(1995). Educação ambiental integrada a coleta seletiva de lixo. Monografia (Especialização em Educação Ambiental), Universidade Estadual da Paraíba, Campina Grande, Brasil.

Silva, P. A. V. B., \& Araújo, M. S. T. (2012). Abordagem de Temas de Educação Ambiental sob o Enfoque CTSA no Ensino Médio no Município de BarueriSP. Anais do II Seminário Hispano Brasileiro, 431-443.

Silva, R. P., \& Batista, M. S. S.(2016). Arte e educação ambiental como possibilidades de desenvolvimento da consciência crítica. Educere,. 11(22). 
Research, Society and Development, v. 10, n. 7, e53810716704, 2021

(CC BY 4.0) | ISSN 2525-3409 | DOI: http://dx.doi.org/10.33448/rsd-v10i7.16704

Silva, M. J., Fernandes, L. S., \&Campos, A. F. (2014). Situação-problema como estratégia didática na abordagem do tema lixo. Revista Educação Ambiental em Ação, (50), p. 1-8.

Siqueira, V. S., \& Arrial, L. R. (2018). Educação ambiental através da reutilização de resíduos sólidos para a elaboração de brinquedos. Thema, 15 (3), $927-$ 942.

Supo, J. (2012). Cómo validar un instrumento - La guía para validar un instrumento en 10 pasos. Biblioteca Nacional del Perú. 